\title{
Rubrik Soeara Moehammadijah 1939-1942
}

\section{Endy Saputro}

IAIN Surakarta

email: endysa@gmail.com

\section{Eka Riowati}

IAIN Surakarta

email: ekariowati I @ @gmail.com

Soeara Moehammadijah, (later: Suara Muhammadiyah), has continuously become one of the longest living magazines in Indonesia. To date, the beginning of publication of Soeara Moehammadijah was published on 1915 and has progressively scattered information to the present day. Several dissertations have used this magazine for one of its main references. Several books have also examined how Muhammadiyah developed, either from education or da'wah, from this source. However, what is the actual content of this magazine, not many have studied it. This series presents the contents of the Soeara Moehammadijah column 1915 - 1940. This section presents the continuous sections of the rubric 1939-1942 


\begin{tabular}{|c|c|c|c|c|}
\hline \multirow{2}{*}{\begin{tabular}{l}
\multicolumn{1}{|c}{\begin{tabular}{c}
\multicolumn{1}{c}{ NOMOR } \\
FILE
\end{tabular}} \\
$\begin{array}{l}\text { Soeara } \\
\text { Moehammadijah } \\
31\end{array}$
\end{tabular}} & $\begin{array}{l}\text { JUDUL DAN } \\
\text { PENERBIT }\end{array}$ & KONTEN & \multicolumn{2}{|c|}{ HALAMAN } \\
\hline & $\begin{array}{l}\text { Soeara } \\
\text { Moehammadijah }\end{array}$ & $\begin{array}{l}\text { Penjelesaian Congres ke } \\
27\end{array}$ & & 2 \\
\hline $\begin{array}{l}\text { No. } 9 \text { Tahoen ke } \\
20\end{array}$ & & $\begin{array}{l}\text { Penjelesaian Congres } \\
\text { Moehammadijah ke-27 di } \\
\text { Malang }\end{array}$ & 218 & 3 \\
\hline $\begin{array}{l}\mathrm{H} \quad \mathrm{B} \\
\text { Moehammadijah }\end{array}$ & & $\begin{array}{l}\text { Peringatan bagi Congres } \\
\text { ke-27 }\end{array}$ & 219 & 3 \\
\hline $\begin{array}{l}\text { Dz. Qa'dah } 1357 \\
\mathrm{H}\end{array}$ & & $\begin{array}{l}\text { Tjabang dan groep } \\
\text { jang telah mengirimkan } \\
\text { sokonganja kepada } \\
\text { Congres Moehammadijah } \\
\text { ke-27 di Malang }\end{array}$ & 221 & 5 \\
\hline \multirow[t]{7}{*}{ (Januari 1939) } & \begin{tabular}{|ll} 
Penjelesaian & Congres \\
ke 27 & \\
\end{tabular} & & 2 & 20 \\
\hline & & $\begin{array}{l}\text { Penjelesaian Congres } \\
\text { Moehammadijah ke-27 di } \\
\text { Malang }\end{array}$ & 218 & 3 \\
\hline & & $\begin{array}{l}\text { Peringatan bagi Congres } \\
\text { ke-27 }\end{array}$ & 219 & 3 \\
\hline & & $\begin{array}{l}\text { Tjabang dan groep } \\
\text { jang telah mengirimkan } \\
\text { sokonganja kepada } \\
\text { Congres Moehammadijah } \\
\text { ke-27 di Malang }\end{array}$ & 221 & 5 \\
\hline & & Werantwoording & 246 & 20 \\
\hline & & $\begin{array}{l}\text { Telegram dari dan } \\
\text { mengoetjapkan }\end{array}$ & 248 & 21 \\
\hline & Soeara Moehammadijah & Daerah Madioen & 255 & 25 \\
\hline $\begin{array}{ll}\text { No. } 10 & \text { Tahoen } \\
\text { ke } 20 & \\
\end{array}$ & & Daerah Soerabaia & 257 & 26 \\
\hline $\begin{array}{l}\mathrm{H} \quad \mathrm{B} \\
\text { Moehammadijah }\end{array}$ & & Daerah Selebes Selatan & 259 & 27 \\
\hline $\begin{array}{l}\text { Dz. Hidjah } 1357 \\
\text { H }\end{array}$ & & $\begin{array}{l}\text { Sokongan Fonds } \\
\text { Moehadjirin }\end{array}$ & 263 & 29 \\
\hline \multirow[t]{8}{*}{ (Maart 1939) } & Penoetoepan Tahoen & 253 & 24 & 30 \\
\hline & & Nomer jang liwat & 253 & 24 \\
\hline & & Membenarkan kesalahan & 254 & 25 \\
\hline & & Dairah Borneo Timoer & 254 & 25 \\
\hline & & Daerah Madioen & 255 & 25 \\
\hline & & Daerah Soerabaia & 257 & 26 \\
\hline & & Daerah Selebes Selatan & 259 & 27 \\
\hline & & $\begin{array}{l}\text { Sokongan Fonds } \\
\text { Moehadjirin }\end{array}$ & 263 & 29 \\
\hline
\end{tabular}

DINIKA, Volume 3, Number 3, September - December 2018 


\begin{tabular}{|c|c|c|c|c|}
\hline & & Roeangan 'Aisjijah: & 272 & 34 \\
\hline \multirow{4}{*}{ Celebes Selatan } & 264 & 30 & 273 & 34 \\
\hline & & Iboe Tempat & 265 & 30 \\
\hline & & Daerah Semarang & 265 & 30 \\
\hline & & Halaman Pemoeda: & 2 & 39 \\
\hline \multirow[t]{8}{*}{ Ma'loemat } & 267 & 31 & 4 & 40 \\
\hline & & Tournee P.P.H.W. & 267 & 31 \\
\hline & & Pengharapan & 268 & 32 \\
\hline & & Peringatan & 268 & 32 \\
\hline & & $\begin{array}{l}\text { Conferentie pemoeda } \\
\text { dairah Soerabaia ke X }\end{array}$ & 269 & 32 \\
\hline & & $\begin{array}{l}\text { Madrasah } \\
\text { Moehammadijah }\end{array}$ & 272 & 34 \\
\hline & & \begin{tabular}{|l|} 
Fihrasah Soeara \\
Moehammadijah 1357
\end{tabular} & 273 & 34 \\
\hline & Soeara Moehammadijah & Blanco Jaarverslag & 15 & 45 \\
\hline $\begin{array}{l}\text { No. } 1 \text { Tahoen ke } \\
21\end{array}$ & & $\begin{array}{l}\text { Halaman Pemoeda: } \\
\text { Congres }\end{array}$ & 16 & 46 \\
\hline $\begin{array}{l}\mathrm{H} \\
\text { Moehammadijah }\end{array}$ & & Tournee PPHW & 17 & 46 \\
\hline R.Awal $1358 \mathrm{H}$ & & Beaja Madjlis & 17 & 46 \\
\hline \multirow{12}{*}{ (April 1939) } & Fihrasat & & 37 & 46 \\
\hline & & $\begin{array}{l}\text { Pemboekaan Tahoen ke } \\
\text { XXI }\end{array}$ & 1 & 38 \\
\hline & & \begin{tabular}{|l|} 
Daerah Lampoeng dan \\
Palembang
\end{tabular} & 2 & 39 \\
\hline & & $\begin{array}{l}\text { Instructie Madjlis Tabligh } \\
\text { P.K.O Pengadjaran dan } \\
\text { Taman Poestaka }\end{array}$ & 4 & 40 \\
\hline & & $\begin{array}{l}\text { Instructie Madjlis } \\
\text { Pemoeda }\end{array}$ & 6 & 41 \\
\hline & & Instructie Madjlis 'Aisjijah & 8 & 42 \\
\hline & & Goeroe Oerdonantie & 10 & 43 \\
\hline & & Sidang Tanwir & 10 & 43 \\
\hline & & Isi Congres ke-28 & 13 & 44 \\
\hline & & \begin{tabular}{|l|} 
Procesverbal \\
verificatiecommissie 1937 \\
dan verantwoording 1938
\end{tabular} & 15 & 45 \\
\hline & & Blanco Jaarverslag & 15 & 45 \\
\hline & & Halaman Pemoeda: & & 53 \\
\hline \multirow[t]{5}{*}{ Congres } & 16 & 46 & & 54 \\
\hline & & Tournee PPHW & 17 & 46 \\
\hline & & Beaja Madjlis & 17 & 46 \\
\hline & & Daerah Lap. Palembang & 17 & 46 \\
\hline & & Daerah Semarang & 19 & 47 \\
\hline
\end{tabular}

DINIKA, Volume 3, Number 3, September - December 2018 


\begin{tabular}{|c|c|c|c|c|}
\hline & & Daerah Celebes Selatan & 20 & 48 \\
\hline & & Daerah Iboe Tempat & 20 & 48 \\
\hline & & Roeangan 'Aisjijah: & 36 & 62 \\
\hline \multirow[t]{9}{*}{ Congres ke 28} & 23 & 49 & 38 & 63 \\
\hline & & $\begin{array}{l}\text { Daerah Lampoeng } \\
\text { Palembang }\end{array}$ & 24 & 50 \\
\hline & & Terhadap Conferentie & 24 & 50 \\
\hline & & Daerah Celebes Oetara & 25 & 50 \\
\hline & & Daerah Soerabaja & 25 & 50 \\
\hline & & Fonds Moehadjirin & 26 & 51 \\
\hline & & $\begin{array}{l}\text { Procesverbaal } \\
\text { Verificatiecommissie kas } \\
\text { bg. 'Aisjijah } \\
\end{array}$ & 27 & 51 \\
\hline & & Verantwoording & & 53 \\
\hline & & Proces Verbal & & 67 \\
\hline \multirow[t]{2}{*}{$\begin{array}{l}\text { Verificatie } \\
\text { Commissie } \\
\text { kas H.B. } \\
\text { Moehammadijah } \\
\text { dengan sekalian } \\
\text { madjlis- } \\
\text { madjlisnja } \\
\text { tahoen } 1927 \\
\end{array}$} & & 54 & & 68 \\
\hline & Soeara Moehammadijah & Pendapatan Commissie & 44 & 69 \\
\hline $\begin{array}{l}\text { No. } 2 \text { Tahoen ke } \\
21\end{array}$ & & $\begin{array}{l}\text { Halaman Pemoeda: } \\
\text { Oendangan Congres }\end{array}$ & 56 & 75 \\
\hline $\begin{array}{l}\mathrm{H} \quad \mathrm{B} \\
\text { Moehammadijah }\end{array}$ & & $\begin{array}{l}\text { Praeadviesen: } \\
\text { Memoedahkan masoknja } \\
\text { beaja Madjlis }\end{array}$ & 58 & 76 \\
\hline Safar $1358 \mathrm{H}$ & & $\begin{array}{l}\text { Menegakkan Pemoeda } \\
\text { Moehammadijah }\end{array}$ & 59 & 76 \\
\hline \multirow[t]{10}{*}{ (Mei 1939) } & Fihrasat & & 57 & 79 \\
\hline & & $\begin{array}{l}\text { Menetapi waktoe } \\
\text { bersidang }\end{array}$ & 29 & 58 \\
\hline & & Selebes Oetara & 31 & 59 \\
\hline & & Daerah Kediri & 32 & 60 \\
\hline & & Pasisir Timoer & 33 & 60 \\
\hline & & Daerah Banjoemas & 35 & 61 \\
\hline & & $\begin{array}{l}\text { Conferentie bagian-bagian } \\
\text { daearh Banjoemas }\end{array}$ & 36 & 62 \\
\hline & & Daerah Banjoemas & 38 & 63 \\
\hline & & Daerah Djawa Barat & 39 & 63 \\
\hline & & Blanco Jaarverslag & 41 & 64 \\
\hline
\end{tabular}

DINIKA, Volume 3, Number 3, September - December 2018 


\begin{tabular}{|c|c|c|c|c|}
\hline & & $\begin{array}{l}\text { Hoofdcomite Congres } \\
\text { Moehammadijah } \\
\text { Djokjakarta } \\
\end{array}$ & 41 & 64 \\
\hline & & Roeangan 'Aisjijah: & 79 & 86 \\
\hline \multirow{5}{*}{$\begin{array}{l}\text { Daerah } \\
\text { Banjoemas }\end{array}$} & 42 & 65 & 80 & 87 \\
\hline & & Bahagian 'Aisjijah & 42 & 65 \\
\hline & & Symbol Padi & 43 & 65 \\
\hline & & $\begin{array}{l}\text { Sekolah-sekolah } \\
\text { Moehammadijah di } \\
\text { Pakoealaman Kota } \\
\text { Djokjakarta }\end{array}$ & & 67 \\
\hline & Soeara Moehammadijah & $\begin{array}{l}\text { Praeadvie Ichtiar } \\
\text { memperbaiki masjarakan } \\
\text { perempoean }\end{array}$ & 84 & 89 \\
\hline $\begin{array}{l}\text { No. } 3 \text { Tahoen ke } \\
21\end{array}$ & & $\begin{array}{l}\text { Praeadvies memperbaiki } \\
\text { oeroesan pendidikan }\end{array}$ & 88 & 91 \\
\hline $\begin{array}{l}\mathrm{H} \quad \mathrm{B} \\
\text { Moehammadijah }\end{array}$ & & $\begin{array}{l}\text { Voorstel-voorstel } \\
\text { perbaikan perhoeboengan } \\
\text { roemah tangga }\end{array}$ & 89 & 91 \\
\hline R.Achir $1358 \mathrm{H}$ & & $\begin{array}{l}\text { Pendapatan- } \\
\text { pendapatan dari pers } \\
\text { dan perhimpoenan- } \\
\text { perhimpoenan Isteri } \\
\text { Islam tentang tambahnja } \\
\text { kemadjoean 'Aisjijah } \\
\text { 'Oemoem } \\
\end{array}$ & 89 & 92 \\
\hline \multirow[t]{4}{*}{ (Juni 1939) } & Fihrasat & & 67 & 93 \\
\hline & & Oendangan Congres & & 68 \\
\hline & & Pendapatan Commissie & 44 & 69 \\
\hline & & Halaman Pemoeda: & 127 & 12 \\
\hline \multirow[t]{2}{*}{$\begin{array}{l}\text { Oendangan } \\
\text { Congres }\end{array}$} & 56 & 75 & 127 & 12 \\
\hline & & Praeadviesen: & 128 & 13 \\
\hline \multirow[t]{7}{*}{$\begin{array}{l}\text { Memoedahkan } \\
\text { masoknja beaja } \\
\text { Madjlis }\end{array}$} & 58 & 76 & 131 & 14 \\
\hline & & $\begin{array}{l}\text { Menegakkan Pemoeda } \\
\text { Moehammadijah }\end{array}$ & 59 & 76 \\
\hline & & Uniform Penghela & 64 & 79 \\
\hline & & $\begin{array}{l}\text { H.W. ta' boleh masoek } \\
\text { kepandoean lain }\end{array}$ & 65 & 79 \\
\hline & & Kekoasaan P.P.H.W & 65 & 79 \\
\hline & & Oesoel-oesoel & 66 & 80 \\
\hline & & Praeadviesan: & 146 & 22 \\
\hline
\end{tabular}




\begin{tabular}{|c|c|c|c|c|}
\hline Langsoengnja & 68 & 81 & 147 & 22 \\
\hline & & Kedoedoekan M. Tardjih & 69 & 81 \\
\hline & & $\begin{array}{l}\text { Praeadvies Kedoedoekan } \\
\text { Pemimpin-pemimpin } \\
\text { dalam daerah terhadap } \\
\text { madjlis-madjlisnja }\end{array}$ & 71 & 82 \\
\hline & & $\begin{array}{l}\text { Praeadvies tjara } \\
\text { memperloeas } \\
\text { Moehammadijah ditanah } \\
\text { Zelfbestuur }\end{array}$ & 72 & 83 \\
\hline & & $\begin{array}{l}\text { Rantjangan Pondok } \\
\text { Moehammadijah }\end{array}$ & 73 & 83 \\
\hline & & $\begin{array}{l}\text { Praeadvies tentang } \\
\text { Leerplan agama madrasah } \\
\text { Moehammadijah se } \\
\text { Indonesia }\end{array}$ & 75 & 84 \\
\hline & & $\begin{array}{l}\text { Praeadvies Plan 3th. } \\
\text { Oentoek pemberantasan } \\
\text { boeta hoeroef dalam } \\
\text { Moehammadijah }\end{array}$ & 76 & 85 \\
\hline & & Roeangan 'Aisjijah: & 155 & 26 \\
\hline $\begin{array}{l}\text { Oendanga } \\
\text { Congres }\end{array}$ & 79 & 86 & 156 & 27 \\
\hline & & $\begin{array}{l}\text { Praeadviesen Oesaha } \\
\text { perloasan penjiaran } \\
\text { Agama Islam dalam } \\
\text { masjarakat kaoem Iboe }\end{array}$ & 80 & 87 \\
\hline & & $\begin{array}{l}\text { ‘Aisjijah andoeng } \\
\text { perloekah 'Aisjijah masoek } \\
\text { Tardjih? }\end{array}$ & 81 & 87 \\
\hline & & $\begin{array}{l}\text { Praeadvies bagaimana } \\
\text { tjara memperloas pintoe } \\
\text { 'Aisjiijah }\end{array}$ & 82 & 88 \\
\hline & & $\begin{array}{l}\text { Praeadvies memilih } \\
\text { gerakan jang dinomenikan }\end{array}$ & 84 & 89 \\
\hline & & $\begin{array}{l}\text { Praeadvie Ichtiar } \\
\text { memperbaiki masjarakan } \\
\text { perempoean }\end{array}$ & 84 & 89 \\
\hline & & $\begin{array}{l}\text { Praeadvies memperbaiki } \\
\text { oeroesan pendidikan }\end{array}$ & 88 & 91 \\
\hline & & $\begin{array}{l}\text { Voorstel-voorstel } \\
\text { perbaikan perhoeboengan } \\
\text { roemah tangga }\end{array}$ & 89 & 91 \\
\hline
\end{tabular}

DINIKA, Volume 3, Number 3, September - December 2018 


\begin{tabular}{|c|c|c|c|c|}
\hline & & $\begin{array}{l}\text { Pendapatan- } \\
\text { pendapatan dari pers } \\
\text { dan perhimpoenan- } \\
\text { perhimpoenan Isteri } \\
\text { Islam tentang tambahnja } \\
\text { kemadjoean 'Aisjijah } \\
\text { 'Oemoem }\end{array}$ & 89 & 92 \\
\hline & & $\begin{array}{l}\text { Ma'loemat H.C.C.M. dan } \\
\text { C.V.O. }\end{array}$ & 92 & 93 \\
\hline \multirow{3}{*}{$\begin{array}{l}\text { Soeara } \\
\text { Moehammadijah } \\
32 \\
\end{array}$} & & Keterangan & $\mathrm{F}$ & 2 \\
\hline & & Ma'loemaat Ketiga & $\mathrm{V}$ & 10 \\
\hline & Soeara Moehammadijah & Daerah Madoera & 169 & 33 \\
\hline $\begin{array}{l}\text { No. 4-5 Tahoen } \\
\text { ke 21 }\end{array}$ & & $\begin{array}{l}\text { Penerimaan wang fonds } \\
\text { Moehadjirin }\end{array}$ & 171 & 34 \\
\hline $\begin{array}{l}\mathrm{H} \\
\text { Moehammadijah }\end{array}$ & & Daerah Tapanoeli & 173 & 35 \\
\hline $\begin{array}{l}\text { Radjab-Sja'ban } \\
1358 \mathrm{H}\end{array}$ & & Daerah Selebes Selatan & 175 & 36 \\
\hline \multirow[t]{14}{*}{$\begin{array}{l}\text { (September- } \\
\text { october 1939) }\end{array}$} & \begin{tabular}{|l} 
Moelai Poeasa dan \\
Lebarannja
\end{tabular} & 127 & 12 & 38 \\
\hline & & Hisab Haqiqi & 127 & 12 \\
\hline & & Daerah Atjeh & 128 & 13 \\
\hline & & Toentoenan jang kedoea & 131 & 14 \\
\hline & & Daerah Minangkabau & 132 & 15 \\
\hline & & Daerah Soerakarta & 133 & 15 \\
\hline & & $\begin{array}{l}\text { Daerah Lampoeng } \\
\text { Palembang }\end{array}$ & 134 & 16 \\
\hline & & Daerah Benkoelen & 138 & 18 \\
\hline & & Daerah Borneo Salatan & 141 & 19 \\
\hline & & Daerah Besoeki & 146 & 22 \\
\hline & & Tanda Sekoetoe & 147 & 22 \\
\hline & & Memoeka alas-kaki & 149 & 23 \\
\hline & & Kelambatan oeroesan & 149 & 23 \\
\hline & & Halaman Pemoeda: & 190 & 44 \\
\hline \multirow{7}{*}{$\begin{array}{l}\text { Pergantian } \\
\text { alamat }\end{array}$} & 150 & 24 & 191 & 44 \\
\hline & & Di Celebes Oetara & 150 & 24 \\
\hline & & Di Djawa Barat & 151 & 24 \\
\hline & & Di Minangkabau & 153 & 25 \\
\hline & & Daerah Kediri & 155 & 26 \\
\hline & & Daerah Atjeh & 156 & 27 \\
\hline & & Roeangan 'Aisjijah: & 195 & 46 \\
\hline
\end{tabular}

DINIKA, Volume 3, Number 3, September - December 2018 


\begin{tabular}{|c|c|c|c|c|}
\hline Daerah Kediri & 159 & 28 & 196 & 47 \\
\hline & & Daerah Atjeh & 159 & 28 \\
\hline & & Daerah Madoera & 160 & 29 \\
\hline & & Daerah Banjoemas & 161 & 29 \\
\hline & & Daerah Besoeki & 161 & 29 \\
\hline & & Daerah Tapanoeli & 162 & 30 \\
\hline & & Daerah Minangkabau & 162 & 30 \\
\hline & & $\begin{array}{l}\text { Hoodfcomite Congres } \\
\text { Moehammadijah } \\
\text { Djokjakarta } \\
\end{array}$ & 164 & 31 \\
\hline & & Kitab ke-cingres-an & 166 & 32 \\
\hline & Soeara Moehammadijah & $\begin{array}{l}\text { Penjelesaian Congres ke } \\
28\end{array}$ & & 2 \\
\hline $\begin{array}{l}\text { No. } 7 \text { Tahoen ke } \\
21\end{array}$ & & \begin{tabular}{|l} 
Pemandangan Congres \\
Moehammadijah ke-28 di \\
Medan \\
\end{tabular} & 3 & 3 \\
\hline $\begin{array}{l}\text { H.B. } \\
\text { Moehammadijah }\end{array}$ & & $\begin{array}{l}\text { Gambar-gambar Congres } \\
\text { Moehammadijah ke-28 di } \\
\text { Medan }\end{array}$ & 17 & 10 \\
\hline Sjawal $1358 \mathrm{H}$ & & $\begin{array}{l}\text { Tanda perhatian kepada } \\
\text { Congress }\end{array}$ & 25 & 14 \\
\hline \multirow{7}{*}{$\begin{array}{l}\text { (November } \\
1939)\end{array}$} & Daerah Pasoereoan & 167 & 32 & 16 \\
\hline & & Daerah Semarang & 168 & 33 \\
\hline & & Daerah Madoera & 169 & 33 \\
\hline & & $\begin{array}{l}\text { Penerimaan wang fonds } \\
\text { Moehadjirin }\end{array}$ & 171 & 34 \\
\hline & & Daerah Tapanoeli & 173 & 35 \\
\hline & & Daerah Selebes Selatan & 175 & 36 \\
\hline & & Halaman Pemoeda: & 53 & 28 \\
\hline \multirow{9}{*}{$\begin{array}{l}\text { Tanfidz } \\
\text { Kapoetoesan } \\
\text { Congres ke-28 } \\
\end{array}$} & 178 & 38 & 56 & 30 \\
\hline & & \begin{tabular}{|l|} 
Pemoeda Moehammadijah \\
dalam organisatie \\
Moehammadijah
\end{tabular} & 178 & 38 \\
\hline & & $\begin{array}{l}\text { Pengoemoeman tentang } \\
\text { "Perkino" }\end{array}$ & 179 & 38 \\
\hline & & Daerah Banjoemas & 179 & 38 \\
\hline & & Daerah Semarang & 181 & 39 \\
\hline & & Daerah Tapanoeli & 183 & 40 \\
\hline & & Daerah Pasoeroean & 184 & 41 \\
\hline & & Daerah Iboe Tempat & 185 & 41 \\
\hline & & Roeangan 'Aisjijah: & 65 & 34 \\
\hline
\end{tabular}

DINIKA, Volume 3, Number 3, September - December 2018 


\begin{tabular}{|c|c|c|c|c|}
\hline \begin{tabular}{|l} 
Daerah \\
Soerakarta
\end{tabular} & 187 & 42 & 67 & 35 \\
\hline & & Daerah Boerneo Selatan & 188 & 43 \\
\hline & & Daerah Selebes Selatan & 188 & 43 \\
\hline & & Tahoenan S.A. & 189 & 43 \\
\hline & & Daerah Pasoeroean & 189 & 43 \\
\hline & & Raport Moment & 190 & 44 \\
\hline & Soeara Moehammadijah & $\begin{array}{l}\text { Congres Akbar ke-29 } \\
\text { pada achir Juli } 1940 \text { di } \\
\text { Djokjakarta }\end{array}$ & 72 & 38 \\
\hline $\begin{array}{l}\text { No. } 8 \text { Tahoen } \\
\text { ke } 21\end{array}$ & & $\begin{array}{l}\text { Verslag Tahoenan } 1939 \\
\text { Haraplah diperhatikan! }\end{array}$ & 73 & 38 \\
\hline $\begin{array}{l}\text { H.B. } \\
\text { Moehammadijah }\end{array}$ & $\begin{array}{l}\text { Soeara } \\
\text { Moehammadijah } \\
\text { No. } 3 \text { Tahoen ke } 22 \\
\text { H.B. Moehammadijah } \\
\text { R. Awal 1359 H } \\
\text { (April 1940) }\end{array}$ & Sidang tanwir & & 41 \\
\hline \begin{tabular}{|l|} 
Dzoel- \\
Qa'idah1358 H \\
\end{tabular} & & $\begin{array}{l}\text { Pengoeroesan hak milik } \\
\text { tanah }\end{array}$ & 81 & 42 \\
\hline (December & Hari raja Adlha & 191 & 44 & 42 \\
\hline & & Daerah Iboe Tempat & 191 & 44 \\
\hline & & Daerah Soerakarta & 192 & 45 \\
\hline & & Daerah Iboe Tempat & 193 & 45 \\
\hline & & $\begin{array}{l}\text { Peneriamaan wang fonds } \\
\text { Moehadjirin }\end{array}$ & 194 & 46 \\
\hline & & Blanco verslag 1939 & 194 & 46 \\
\hline & & Halaman Pemoeda: & 87 & 46 \\
\hline Seroean dan & 195 & 46 & 88 & 46 \\
\hline & & $\begin{array}{l}\text { Toentoenan organisatie } \\
\text { Pemoeda Moehammadijah }\end{array}$ & 196 & 47 \\
\hline & & $\begin{array}{l}\text { Toeroenan soerat siaran } \\
\text { tentang perhoeboengan } \\
\text { dengan K.P.I. }\end{array}$ & 197 & 47 \\
\hline & & Daerah Soerabaja & 198 & 48 \\
\hline & & Daerah Selebes Selatan & 199 & 48 \\
\hline & & Roewangan 'Aisjijah & 201 & 49 \\
\hline & & Penerimaan Boekoe & 202 & 50 \\
\hline & & Sedikit Peringatan & 202 & 50 \\
\hline & & $\begin{array}{l}\text { Kandoengan Almanak } \\
\text { Moehammadijah jang ke } \\
\text { XVII }\end{array}$ & & 52 \\
\hline
\end{tabular}




\begin{tabular}{|c|c|c|c|c|}
\hline \begin{tabular}{|l|} 
Soara \\
Moehammadijah \\
33
\end{tabular} & Soeara Moehammadijah & Ma'loemat ke II & 96 & 50 \\
\hline \begin{tabular}{|l|} 
No. 1 Tahoen ke \\
22
\end{tabular} & & Verantwoording & & 51 \\
\hline \begin{tabular}{|l|} 
H.B. \\
Moehammadijah
\end{tabular} & $\begin{array}{l}\text { Soeara } \\
\text { Moehammadijah } \\
\text { No. 4 Tahoen ke } 22 \\
\text { H.B. Moehammadijah } \\
\text { R. Achir 1359 H } \\
\text { (Mei 1940) }\end{array}$ & $\begin{array}{l}\text { Congres Moehammadijah } \\
\text { ke-29 }\end{array}$ & 97 & 52 \\
\hline $\begin{array}{l}\text { Moeharram } \\
1359 \mathrm{H}\end{array}$ & & $\begin{array}{l}\text { Tambahan isi Congres } \\
\text { ke-29 }\end{array}$ & 97 & 52 \\
\hline \multirow[t]{16}{*}{ (Februari 1940) } & Pemboekaan Tahoen & & 2 & 53 \\
\hline & & \begin{tabular}{|l} 
Penjelesaian Congres ke \\
28
\end{tabular} & & 2 \\
\hline & & $\begin{array}{l}\text { Pemandangan Congres } \\
\text { Moehammadijah ke-28 di } \\
\text { Medan }\end{array}$ & 3 & 3 \\
\hline & & $\begin{array}{l}\text { Gambar-gambar Congres } \\
\text { Moehammadijah ke-28 di } \\
\text { Medan }\end{array}$ & 17 & 10 \\
\hline & & $\begin{array}{l}\text { Tanda perhatian kepada } \\
\text { Congress }\end{array}$ & 25 & 14 \\
\hline & & $\begin{array}{l}\text { Derma dan hadiah kepada } \\
\text { Congress }\end{array}$ & 29 & 16 \\
\hline & & $\begin{array}{l}\text { Sokongan kewadjiban } \\
\text { kepada Congres }\end{array}$ & 36 & 20 \\
\hline & & Soesoelan sokongan & 48 & 26 \\
\hline & & Peringatan & 48 & 26 \\
\hline & & $\begin{array}{l}\text { Beberapa perkara jang } \\
\text { kedjadian sehabis Congres }\end{array}$ & 49 & 26 \\
\hline & & $\begin{array}{l}\text { Kita dan Zelfbertuurders } \\
\text { di Atjeh } \\
\end{array}$ & 50 & 27 \\
\hline & & $\begin{array}{l}\text { Kematian HR. } \\
\text { Moehammad Said } \\
\end{array}$ & 53 & 28 \\
\hline & & Boeah Congres ke 28 & 56 & 30 \\
\hline & & Kitab-kitab ke-congres-an & 57 & 30 \\
\hline & & Congres Akbar ke 29 & 58 & 31 \\
\hline & $\begin{array}{l}\text { Soeara } \\
\text { Moehammadijah }\end{array}$ & $\begin{array}{l}\text { Sebab Pengoendoeran } \\
\text { waktoe Congres }\end{array}$ & 121 & 64 \\
\hline $\begin{array}{l}\text { No. } 2 \text { Tahoen ke } \\
22\end{array}$ & & $\begin{array}{l}\text { Menambah candidaat } \\
\text { anggauta H.B. }\end{array}$ & 121 & 64 \\
\hline \begin{tabular}{l|} 
H.B. \\
Moehammadijah
\end{tabular} & & $\begin{array}{l}\text { Daerah Lampeng } \\
\text { Palembang }\end{array}$ & 122 & 65 \\
\hline
\end{tabular}

DINIKA, Volume 3, Number 3, September - December 2018 


\begin{tabular}{|c|c|c|c|c|}
\hline Shafar $1359 \mathrm{H}$ & & \begin{tabular}{|l}
$\begin{array}{l}\text { Penerimaan Fonds } \\
\text { Moehadjirin }\end{array}$ \\
\end{tabular} & 128 & 68 \\
\hline \multirow[t]{5}{*}{ (Maart 1940) } & $\begin{array}{l}\text { Qo'idah H.B. } \\
\text { Mo e ha m m a dija h } \\
\text { Madjlis } \\
\text { Poestaka Taman } \\
\text { "Persoerat Chabaran } \\
\text { Moeh a m m a dijah } \\
\text { Indonesia (Persmi)" } \\
\end{array}$ & 59 & 31 & 68 \\
\hline & & Daerah Borneo Timoer & 60 & 32 \\
\hline & & Daerah Soerabaia & 61 & 32 \\
\hline & & Daerah Semarang & 63 & 33 \\
\hline & & Halaman Pemoeda: & 134 & 71 \\
\hline \multirow[t]{6}{*}{$\begin{array}{l}\text { Ma'loemat } \\
\text { perlombaan } \\
\text { akbar dalam } \\
\text { Congres ke-29 } \\
\text { jang akan datang }\end{array}$} & 65 & 34 & 134 & 71 \\
\hline & & Daerah Madioen & 65 & 34 \\
\hline & & Daerah Borneo Timoer & 67 & 35 \\
\hline & & Daerah Semarang & 68 & 36 \\
\hline & & Daerah Soerabaja & 69 & 36 \\
\hline & & Roewangan 'Aisjijah: & 146 & 77 \\
\hline \multirow[t]{5}{*}{$\begin{array}{l}\text { Sesoedah selesai, } \\
\text { menoedjoe jang } \\
\text { lain lagi dari dan } \\
\text { kepada Congres }\end{array}$} & 70 & 37 & 148 & 78 \\
\hline & & Daerah Borneo Timoer & 71 & 37 \\
\hline & & $\begin{array}{l}\begin{array}{l}\text { Bahagian 'Aisjijah jang } \\
\text { berarti }\end{array} \\
\end{array}$ & 71 & 37 \\
\hline & & \begin{tabular}{|l|} 
Congres Akbar ke-29 \\
pada achir Juli 1940 di \\
Djokjakarta \\
\end{tabular} & 72 & 38 \\
\hline & & Verslag Tahoenan 1939 & 152 & 80 \\
\hline \multirow{2}{*}{$\begin{array}{l}\text { Haraplah } \\
\text { diperhatikan! }\end{array}$} & 73 & 38 & 154 & 81 \\
\hline & Soeara Moehammadijah & $\begin{array}{l}\text { Halaman Pemoeda: } \\
\text { Pendjelasan dan } \\
\text { toentoenan dar P.P.H.W. }\end{array}$ & 157 & 82 \\
\hline \begin{tabular}{|l} 
No. 3 Tahoen ke \\
22
\end{tabular} & & Daerah Minangkabau & 158 & 83 \\
\hline \begin{tabular}{|l} 
H.B. \\
Moehammadijah
\end{tabular} & & Daerah Atjeh & 158 & 83 \\
\hline R. Awal $1359 \mathrm{H}$ & & Daerah Semarang & 159 & 83 \\
\hline
\end{tabular}

DINIKA, Volume 3, Number 3, September - December 2018 


\begin{tabular}{|c|c|c|c|c|}
\hline \multirow[t]{9}{*}{ (April 1940) } & Sidang tanwir & & 41 & 84 \\
\hline & & $\begin{array}{l}\text { Pengoeroesan hak milik } \\
\text { tanah }\end{array}$ & 81 & 42 \\
\hline & & Tanfidz Kitab Shijam & 81 & 42 \\
\hline & & $\begin{array}{l}\text { Qa'idah Madjlis Tardjih } \\
\text { Moehammadijah }\end{array}$ & 82 & 43 \\
\hline & & $\begin{array}{l}\text { Perbaikan instructive } \\
\text { Madjlis Pemoeda }\end{array}$ & 84 & 44 \\
\hline & & Isi Congres ke-29 & 84 & 44 \\
\hline & & $\begin{array}{l}\text { Isi Besloten Congres } \\
\text { Moehammadijah }\end{array}$ & 84 & 44 \\
\hline & & Hal tabir dalam sidang & 85 & 44 \\
\hline & & Roewangan 'Aisjijah: & 175 & 91 \\
\hline \multirow{5}{*}{$\begin{array}{ll}\text { Oendangan dan } \\
\text { isi Congres ke- } \\
29 & \\
\end{array}$} & 87 & 46 & 176 & 92 \\
\hline & & Voorstel-voorstel & 88 & 46 \\
\hline & & Tahoenan Soeara 'Aisjijah & 88 & 46 \\
\hline & & Bahagian 'Aisjijah & 89 & 46 \\
\hline & & Halaman Pemoeda: & 182 & 95 \\
\hline \multirow[t]{6}{*}{$\begin{array}{ll}\text { Oendangan ke } \\
\text { Congress }\end{array}$} & 90 & 47 & 183 & 95 \\
\hline & & $\begin{array}{l}\text { Pengoemoem tentang } \\
\text { "Perkino" }\end{array}$ & 91 & 47 \\
\hline & & Pergantian Adres & 91 & 47 \\
\hline & & Keoeangan & 91 & 47 \\
\hline & & Daerah Pekalongan & 92 & 48 \\
\hline & & Ma'loemat ke I & 186 & 97 \\
\hline \multirow{4}{*}{$\begin{array}{l}\text { Congres Akbar } \\
\text { Moehammadijah } \\
\text { ke-29 }\end{array}$} & 95 & 49 & 188 & 98 \\
\hline & & Ma’loemat ke II & 96 & 50 \\
\hline & & Verantwoording & & 51 \\
\hline & Soeara Moehammadijah & $\begin{array}{l}\text { Toentoenan gerakan dan } \\
\text { boelan Ramadlan }\end{array}$ & 192 & 100 \\
\hline $\begin{array}{l}\text { No. } 4 \text { Tahoen ke } \\
22\end{array}$ & & Daerah Iboe Tempat & 193 & 100 \\
\hline $\begin{array}{l}\text { H.B. } \\
\text { Moehammadijah }\end{array}$ & $\begin{array}{l}\text { Soeara } \\
\text { Moehammadijah } \\
\text { No. } 9 \text { Tahoen ke } 22 \\
\text { H.B. Moehammadijah } \\
\text { Ramadlan } 1359 \text { H } \\
\text { (October 1940) }\end{array}$ & Perintah Hoofdbestuur & 195 & 101 \\
\hline R. Achir $1359 \mathrm{H}$ & & Congres ke-20 & 196 & 2 \\
\hline
\end{tabular}

DINIKA, Volume 3, Number 3, September - December 2018 


\begin{tabular}{|c|c|c|c|c|}
\hline (Mei 1940) & $\begin{array}{|lllllll|}\mathrm{C} & \mathrm{o} & \mathrm{n} & \mathrm{g} & \mathrm{r} & \mathrm{e} & \mathrm{s} \\
\text { Moeh } & & & & & & \end{array}$ & 97 & 52 & 2 \\
\hline & & $\begin{array}{l}\text { Tambahan isi Congres } \\
\text { ke-29 }\end{array}$ & 97 & 52 \\
\hline & & Daerah Banjoemas & 98 & 53 \\
\hline & & Daerah Celebes Oetara & 99 & 53 \\
\hline & & $\begin{array}{l}\text { Daerah Sumatera Pasisir } \\
\text { Timoer }\end{array}$ & 100 & 54 \\
\hline & & Daerah Madoera & 101 & 54 \\
\hline & & Daerah Tapanoeli & 103 & 55 \\
\hline & & Daerah Minangkabau & 105 & 56 \\
\hline & & Daerah Benkoelen & 107 & 57 \\
\hline & & $\begin{array}{l}\text { Pengoendoeran waktoe } \\
\text { Congres ke } 29 \text { dan } \\
\text { peringatan jang perloe }\end{array}$ & 108 & 58 \\
\hline & & Halaman Pemoeda: & & 13 \\
\hline \multirow{8}{*}{$\begin{array}{l}\text { Pengoemoeman } \\
\text { dan pendjelasan } \\
\text { dari P.P.H.W. } \\
\end{array}$} & 109 & 58 & 214 & 14 \\
\hline & & $\begin{array}{l}\text { Perlengkapan keperloean } \\
\text { Congres }\end{array}$ & 109 & 58 \\
\hline & & $\begin{array}{l}\text { Daerah Soematra Pesisir } \\
\text { Timoer }\end{array}$ & 111 & 59 \\
\hline & & Daerah Minangkabau & 114 & 61 \\
\hline & & Daerah Banjoemas & 116 & 62 \\
\hline & & Daerah Selebes Oetara & 118 & 63 \\
\hline & & $\begin{array}{l}\text { Madrasah Moe'alimien } \\
\text { Moehammadijah }\end{array}$ & 120 & 64 \\
\hline & Soeara Moehammadijah & $\begin{array}{l}\text { Praeadvies hal: tjara } \\
\text { memperboeah achlaq } \\
\text { menoeroet toentoenan } \\
\text { Nabi kepada sekoeto } \\
\text { 'Aisjiijah }\end{array}$ & 226 & 20 \\
\hline $\begin{array}{l}\text { No. } 5 \text { Tahoen ke } \\
22\end{array}$ & & Voorstel-voorstel & 229 & 21 \\
\hline $\begin{array}{l}\text { H.B. } \\
\text { Moehammadijah }\end{array}$ & & $\begin{array}{l}\text { Halaman Pemoeda: } \\
\text { Oendangan ke Congress }\end{array}$ & 230 & 22 \\
\hline Dj. Awal $1359 \mathrm{H}$ & & $\begin{array}{l}\text { Praeadvies: } \\
\text { perhoeboengan madjlis } \\
\text { pemoeda dengan party } \\
\text { lain }\end{array}$ & 231 & 22 \\
\hline \multirow[t]{2}{*}{ (Juni 1940) } & \begin{tabular}{|l|} 
Sebab Pengoendoeran \\
waktoe Congres
\end{tabular} & 121 & 64 & 23 \\
\hline & & $\begin{array}{l}\text { Menambah candidaat } \\
\text { anggauta H.B. }\end{array}$ & 121 & 64 \\
\hline
\end{tabular}




\begin{tabular}{|c|c|c|c|c|}
\hline & & \begin{tabular}{|l|}
$\begin{array}{l}\text { Daerah Lampeng } \\
\text { Palembang }\end{array}$ \\
\end{tabular} & 122 & 65 \\
\hline & & \begin{tabular}{|l|}
$\begin{array}{l}\text { Penerimaan Fonds } \\
\text { Moehadjirin }\end{array}$ \\
\end{tabular} & 128 & 68 \\
\hline & & \begin{tabular}{|l|}
$\begin{array}{l}\text { Penerimaan verslag } \\
\text { tahoenan } 1939\end{array}$ \\
\end{tabular} & 129 & 68 \\
\hline & & $\begin{array}{l}\text { Tjara pembebasan blasting } \\
\text { qoerban }\end{array}$ & 132 & 70 \\
\hline & & Halaman Pemoeda: & 237 & 25 \\
\hline \multirow[t]{7}{*}{ Ma'loemat } & 133 & 70 & 238 & 26 \\
\hline & & Toentoenan & 133 & 70 \\
\hline & & Daerah Benkoelen & 134 & 71 \\
\hline & & Daerah Tapanoeli & 134 & 71 \\
\hline & & $\begin{array}{l}\text { Daerah Lampoeng } \\
\text { Palembang }\end{array}$ & 136 & 72 \\
\hline & & Sedikit Pendjelasan & 139 & 73 \\
\hline & Soeara Moehammadijah & Mandaat Oetoesan & 249 & 31 \\
\hline $\begin{array}{l}\text { No. } 6 \text { Tahoen ke } \\
22\end{array}$ & & Bilangannja Oetoesan & 250 & 32 \\
\hline $\begin{array}{lc}\mathrm{H} & \mathrm{B} \\
\text { Moehammadijah }\end{array}$ & & Sokongan Congres & 251 & 32 \\
\hline $\begin{array}{l}\text { Dj. Achir } 1359 \\
\mathrm{H}\end{array}$ & $\begin{array}{l}\text { Soeara } \\
\text { Moehammadijah } \\
\text { No. 11 Tahoen ke } 22 \\
\text { H.B. Moehammadijah } \\
\text { Dz. Qa'dah 1359 H } \\
\text { (December 1940) }\end{array}$ & Peringatan & 253 & 33 \\
\hline \multirow[t]{3}{*}{ (Juli 1940) } & Daerah Atjeh & 141 & 74 & 34 \\
\hline & & Bahagian Pemoeda & 142 & 75 \\
\hline & & Roeangan 'Aisjijah: & 257 & 35 \\
\hline \multirow[t]{8}{*}{$\begin{array}{l}\text { Handleiding } \\
\text { pemimpin } \\
\text { Nasjiatoel } \\
\text { 'Aisjijah } \\
\end{array}$} & 146 & 77 & 260 & 37 \\
\hline & & Daerah Madoera & 148 & 78 \\
\hline & & Daerah Tapanoeli & 149 & 78 \\
\hline & & $\begin{array}{l}\text { Daerah Lampoeng } \\
\text { Palembang }\end{array}$ & 149 & 78 \\
\hline & & Daerah Celebes Oetara & 150 & 79 \\
\hline & & Daerah Pasisir Timoer & 152 & 80 \\
\hline & & Daerah Minangkabau & 154 & 81 \\
\hline & & Halaman Pemoeda: & 1 & 31 \\
\hline $\begin{array}{l}\text { Pendjelasan dan } \\
\text { toentoenan dar } \\
\text { P.P.H.W. }\end{array}$ & 157 & 82 & 2 & 32 \\
\hline
\end{tabular}

DINIKA, Volume 3, Number 3, September - December 2018 


\begin{tabular}{|c|c|c|c|c|}
\hline & & Daerah Minangkabau & 158 & 83 \\
\hline & & Daerah Atjeh & 158 & 83 \\
\hline & & Daerah Semarang & 159 & 83 \\
\hline & Soeara Moehammadijah & $\begin{array}{l}\text { Tjabang dan Groep } \\
\text { Moehammadijah tahoen } \\
1940\end{array}$ & 17 & 39 \\
\hline $\begin{array}{l}\text { No. } 7 \text { Tahoen ke } \\
22\end{array}$ & & Tjabang dan Groep & 18 & 40 \\
\hline $\begin{array}{l}\text { H.B. } \\
\text { Moehammadijah }\end{array}$ & & $\begin{array}{l}\text { Perhitoengan Tjabang dan } \\
\text { groep Moehammadijah th } \\
1939 \text { sampai } 1940\end{array}$ & 30 & 46 \\
\hline Radjab $1359 \mathrm{H}$ & & $\begin{array}{l}\text { Halaman Pemoeda dan } \\
\text { roewangan 'Aisjijah }\end{array}$ & 31 & 46 \\
\hline \multirow[t]{6}{*}{ (Aug. 1940) } & Bahagian 'Aisjijah & 161 & 84 & 47 \\
\hline & & Daerah Pekalongan & 165 & 86 \\
\hline & & Daerah Djawa Barat & 165 & 86 \\
\hline & & Daerah Semarang & 167 & 87 \\
\hline & & Daerah Borneo Barat & 169 & 88 \\
\hline & & Halaman Pemoeda: & 42 & 52 \\
\hline \multirow[t]{6}{*}{ Pengoemoeman } & 171 & 89 & 45 & 53 \\
\hline & & Daerah Djawa Barat & 171 & 89 \\
\hline & & Daerah Pekalongan & 174 & 91 \\
\hline & & Daerah Kediri & 175 & 91 \\
\hline & & Harap Diperbatikan!!! & 176 & 92 \\
\hline & Soeara Moehammadijah & Sokongan Oentoek S.M. & 54 & 58 \\
\hline $\begin{array}{l}\text { No. } 8 \text { Tahoen ke } \\
22\end{array}$ & & $\begin{array}{l}\text { Roewangan 'Aisjijah: } \\
\text { Daerah Soerabaia }\end{array}$ & 55 & 58 \\
\hline $\begin{array}{l}\text { H.B. } \\
\text { Moehammadijah }\end{array}$ & & $\begin{array}{l}\text { Pengiriman Potoesan } \\
\text { Conferentie }\end{array}$ & 56 & 59 \\
\hline Sja’ban $1359 \mathrm{H}$ & & $\begin{array}{l}\text { Halaman Pemoeda: } \\
\text { Daerah Soerabaja }\end{array}$ & 57 & 59 \\
\hline \multirow[t]{5}{*}{ (Sept. 1940) } & $\begin{array}{l}\text { Permoelaan Ramadlan } \\
\text { dan Sjawal } 1359\end{array}$ & 177 & 92 & \\
\hline & & 'Oelama Tardjih & 177 & 92 \\
\hline & & $\begin{array}{l}\text { Gerakan Ramadlan dan } \\
\text { Hari Raja }\end{array}$ & 181 & 94 \\
\hline & & Pondok Moehammadijah & 182 & 95 \\
\hline & & Roeangan 'Aisjijah: & 61 & \\
\hline \multirow[t]{2}{*}{$\begin{array}{l}\text { Meramaikan } \\
\text { Moeshalla } \\
\text { 'Aisjijah } \\
\end{array}$} & 183 & 95 & 61 & \\
\hline & & $\begin{array}{l}\text { Mempraktikan andjoeran } \\
\text { dalam Congres jang ke-28 } \\
\text { di Medan } \\
\end{array}$ & 183 & 95 \\
\hline
\end{tabular}




\begin{tabular}{|c|c|c|c|c|}
\hline & & $\begin{array}{l}\text { Siaran tentang } \\
\text { pertolongan }\end{array}$ & 184 & 96 \\
\hline & & Toentoenan Berpakaian & 185 & 96 \\
\hline & & Daerah Atjeh & 185 & 96 \\
\hline & & Daerah Banjoemas & 186 & 97 \\
\hline & & Adres Bahagian 'Aisjiah & 188 & 98 \\
\hline & & Halaman Pemoeda: & 73 & \\
\hline \multirow{4}{*}{$\begin{array}{ll}\text { Perigatan } & \text { dan } \\
\text { toentoenan } & \text { dari } \\
\text { P.P.H.W. } & \\
\end{array}$} & 189 & 98 & 74 & \\
\hline & & Adres bahagian Pemoeda & 150 & 99 \\
\hline & & $\begin{array}{l}\text { Toentoenan gerakan dan } \\
\text { boelan Ramadlan }\end{array}$ & 192 & 100 \\
\hline & & Daerah Iboe Tempat & 193 & 100 \\
\hline $\begin{array}{l}\text { Soeara } \\
\text { Moehamadijah } \\
34 \\
\end{array}$ & Soeara Moehammadijah & Daerah Tapanoeli & 78 & 65 \\
\hline $\begin{array}{l}\text { No. } 9 \text { Tahoen ke } \\
22\end{array}$ & & Kas Verantwoording H.B. & 80 & 66 \\
\hline \begin{tabular}{|l} 
H.B. \\
Moehammadijah
\end{tabular} & & Daerah Benkoelen & 81 & 66 \\
\hline $\begin{array}{ll}\text { Ramadlan } 1359 \\
\text { H }\end{array}$ & & Daerah Celebes Selatan & 82 & 67 \\
\hline \multirow[t]{7}{*}{ (October 1940) } & Perintah Hoofdbestuur & 195 & 101 & 70 \\
\hline & & Congres ke-20 & 196 & 2 \\
\hline & & Daerah Kediri & 196 & 2 \\
\hline & & Mandaat Pelantjongan & 199 & 3 \\
\hline & & Daerah Iboe Tempat & 200 & 4 \\
\hline & & $\begin{array}{l}\text { Peratoeran Pengoeroes } \\
\text { Pemiliharaan Masdjid } \\
\text { Moehammadijah di } \\
\text { Djokjakarta } \\
\end{array}$ & 202 & 5 \\
\hline & & Roeangan 'Aisjijah: & 95 & 73 \\
\hline \multirow[t]{2}{*}{$\begin{array}{ll}\text { Daerah } & \text { Iboe } \\
\text { Tempat } & \\
\end{array}$} & 205 & 6 & 95 & 73 \\
\hline & & Halaman Pemoeda: & 96 & 74 \\
\hline \multirow[t]{4}{*}{$\begin{array}{l}\text { Barsiap, } \\
\text { Menoedjoe ke } \\
\text { Congres-29 } \\
\end{array}$} & 207 & 7 & 96 & 74 \\
\hline & & Isi-isi Congress & 207 & 7 \\
\hline & & Perlombaan Akbar & 208 & 8 \\
\hline & & $\begin{array}{l}\text { Hoofdcomite Congres } \\
\text { Moehammadijah }\end{array}$ & 99 & 75 \\
\hline Ma'loemat ke III & 210 & 9 & 101 & 76 \\
\hline
\end{tabular}

DINIKA, Volume 3, Number 3, September - December 2018 


\begin{tabular}{|c|c|c|c|c|}
\hline & & $\begin{array}{l}\text { Candidaat Anggauta H.B. } \\
\text { Moehammadijah }\end{array}$ & 210 & 9 \\
\hline & Soeara Moehammadijah & $\begin{array}{l}\text { Process verbal verificatie } \\
\text { commissie } 1939\end{array}$ & & 79 \\
\hline $\begin{array}{ll}\text { No. } 10 & \text { Tahoen } \\
\text { ke 22 } & \\
\end{array}$ & & Verantwoording & & 79 \\
\hline $\begin{array}{l}\text { H.B. } \\
\text { Moehammadijah }\end{array}$ & $\begin{array}{l}\text { Soeara } \\
\text { Moehammadijah } \\
\text { No. } 5 \text { Tahoen ke } 23 \\
\text { H.B. Moehammadijah } \\
\text { Dj. Awal } 1360 \mathrm{H} \\
\text { (Juni 1941) }\end{array}$ & Fihrasah & & 81 \\
\hline Sawal $1359 \mathrm{H}$ & & Sidang Tanwir & 105 & 82 \\
\hline \multirow{2}{*}{$\begin{array}{l}\text { (November } \\
\text { 1940) }\end{array}$} & Persiapan Congres & & 13 & 83 \\
\hline & & Roewangan 'Aisjijah: & 107 & 83 \\
\hline \multirow{8}{*}{$\begin{array}{l}\text { Oendangan } \\
\text { Congres } \\
\end{array}$} & 214 & 14 & 113 & 86 \\
\hline & & \begin{tabular}{|l|}
$\begin{array}{l}\text { Praeadvies hal: Onkost } \\
\text { Pemimpin 'Aisjijah Daerah }\end{array}$ \\
\end{tabular} & 215 & 14 \\
\hline & & $\begin{array}{l}\text { Praeadvies hal: beroesaha } \\
\text { soepaja sekalian moerid } \\
\text { Moehammadijah Isteri } \\
\text { dapat didikan dari } \\
\text { Nasjiatoel 'Aisjijah } \\
\end{array}$ & 218 & 16 \\
\hline & & $\begin{array}{l}\text { Praeadvies hal: } \\
\text { mengadakan consultatie } \\
\text { Bureau oentoek } \\
\text { membersihkan perkara } \\
\text { oeroesan roemahtangga }\end{array}$ & 220 & 17 \\
\hline & & $\begin{array}{l}\text { Praeadvies hal: bagaimana } \\
\text { tjara menjampaikan } \\
\text { nasjiatoel 'Aisjijah kepada } \\
\text { 'Aisjijahnja }\end{array}$ & 221 & 17 \\
\hline & & $\begin{array}{l}\text { Praeadvies hal: } \\
\text { kelengkapan pembantoe } \\
\text { pemimpin 'Aisjijah daerah }\end{array}$ & 222 & 18 \\
\hline & & $\begin{array}{l}\text { Praeadvies hal: perloekah } \\
\text { diadakan gerakan moment } \\
\text { lagi? Kalau perloe, apakah, } \\
\text { kapan dan bagaimana } \\
\text { tjaranja? }\end{array}$ & 226 & 20 \\
\hline & & $\begin{array}{l}\text { Praeadvies hal: tjara } \\
\text { memperboeah achlaq } \\
\text { menoeroet toentoenan } \\
\text { Nabi kepada sekoeto } \\
\text { 'Aisjijah } \\
\end{array}$ & 226 & 20 \\
\hline
\end{tabular}

DINIKA, Volume 3, Number 3, September - December 2018 


\begin{tabular}{|c|c|c|c|c|}
\hline & & Voorstel-voorstel & 229 & 21 \\
\hline & & Halaman Pemoeda: & 119 & 89 \\
\hline \multirow{10}{*}{$\begin{array}{ll}\text { Oendangan } & \mathrm{ke} \\
\text { Congress } & \\
\end{array}$} & 230 & 22 & 119 & 89 \\
\hline & & $\begin{array}{l}\text { Praeadvies: } \\
\text { perhoeboengan madjlis } \\
\text { pemoeda dengan party } \\
\text { lain }\end{array}$ & 231 & 22 \\
\hline & & $\begin{array}{l}\text { Praeadvies: menentoekan } \\
\text { Gerakan Oemoem boeat } \\
\text { tahoen } 1941\end{array}$ & 232 & 23 \\
\hline & & $\begin{array}{l}\text { Praeadvies: nama-nama } \\
\text { persidangan }\end{array}$ & 233 & 23 \\
\hline & & $\begin{array}{l}\text { praeadvies: perbaikan } \\
\text { djalan ps. H.W. }\end{array}$ & 233 & 23 \\
\hline & & $\begin{array}{l}\text { Praeadvies: mengadakan } \\
\text { Pemoeda Sen }\end{array}$ & 234 & 24 \\
\hline & & $\begin{array}{l}\text { Praeadvies: } \\
\text { menjempoernakan } \\
\text { Djalannja Jamboree } \\
\end{array}$ & 235 & 24 \\
\hline & & \begin{tabular}{|l|} 
Praeadvies: \\
menjempornakan \\
djalannja cursus \\
\end{tabular} & 236 & 25 \\
\hline & & Oendangan Congres & 237 & 25 \\
\hline & & Praeadvies dan voorstel: & 133 & 96 \\
\hline \multirow{7}{*}{$\begin{array}{l}\text { Akan langsoeng } \\
\text { hidoepnja } \\
\text { penerbitan } \\
\text { boekoe-boekoe } \\
\text { sekolahan } \\
\text { Mohammadijah } \\
\end{array}$} & 238 & 26 & 135 & 97 \\
\hline & & $\begin{array}{l}\text { Contributie anggauta } \\
\text { pemoeda Moehammadijah } \\
\text { jang merangkap mendjadi } \\
\text { anggauta Moehammadijah }\end{array}$ & 239 & 26 \\
\hline & & $\begin{array}{l}\text { Perbaikan perdjalanan } \\
\text { Hadji }\end{array}$ & 240 & 27 \\
\hline & & $\begin{array}{l}\text { Perbaikan perdjalanan } \\
\text { Hadji }\end{array}$ & 242 & 28 \\
\hline & & $\begin{array}{l}\text { Gerakan perekonomian } \\
\text { menghadjatkan berdirinja } \\
\text { madjlis perekonomian } \\
\text { Moehammadijah } \\
\end{array}$ & 244 & 29 \\
\hline & & $\begin{array}{l}\text { Oesoel-oesol Congres ke- } \\
29 \text { jang diterima }\end{array}$ & 246 & 30 \\
\hline & & Mandaat Oetoesan & 249 & 31 \\
\hline
\end{tabular}

DINIKA, Volume 3, Number 3, September - December 2018 


\begin{tabular}{|c|c|c|c|c|}
\hline & & Bilangannja Oetoesan & 250 & 32 \\
\hline & & Sokongan Congres & 251 & 32 \\
\hline & Soeara Moehammadijah & Menghadapi batoe oedjian & 149 & 4 \\
\hline $\begin{array}{ll}\text { No. } 11 & \text { Tahoen } \\
\text { ke } 22 & \end{array}$ & & Waktoe berlakoenja & 155 & 7 \\
\hline $\begin{array}{l}\text { H.B. } \\
\text { Moehammadijah }\end{array}$ & & Postelad dan beriefkaart & 155 & 7 \\
\hline $\begin{array}{l}\text { Dz. Qa'dah } 1359 \\
\text { H }\end{array}$ & \begin{tabular}{|l|} 
Soeara \\
Moehammadijah \\
No. 8 Tahoen ke 23 \\
H.B. Moehammadijah \\
Sja'ban 1360 H \\
(Sept. 1941)
\end{tabular} & Fihrasat & & 8 \\
\hline \multirow{9}{*}{$\begin{array}{l}\text { (December } \\
1940)\end{array}$} & Peringatan & 253 & 33 & 9 \\
\hline & & Praeadvies Sekolah Tinggi & 254 & 34 \\
\hline & & $\begin{array}{l}\text { Praeadvies perobbahan } \\
\text { statute dan } \\
\text { huishoudelijk reglement } \\
\text { Moehammadijah }\end{array}$ & 255 & 34 \\
\hline & & $\begin{array}{l}\text { Praeadvies mengadakan } \\
\text { Madjlis Keoeangan } \\
\text { Moehammadijah }\end{array}$ & 257 & 35 \\
\hline & & $\begin{array}{l}\text { Persiapan persedian } \\
\text { Congres Moehammadijah } \\
\text { ke-29 }\end{array}$ & 260 & 37 \\
\hline & & Mandaat Oetoesan & 265 & 39 \\
\hline & & Bilangannja Oetoesan & 266 & 40 \\
\hline & & Sokongan Congres & 267 & 40 \\
\hline & & Soerat soeara pemilihan & 267 & 40 \\
\hline $\begin{array}{l}\text { Soeara } \\
\text { Moehammadijah } \\
35\end{array}$ & & $\begin{array}{l}\text { Programma Congres } \\
\text { Moehammadijah }\end{array}$ & 162 & 14 \\
\hline \multirow[t]{3}{*}{ Congres ke-29 } & & 2 & 166 & 16 \\
\hline & & Pendahoeloean & & 3 \\
\hline & Soeara Moehammadijah & Sokongan dari bg. 'Aisjijah & 168 & 17 \\
\hline $\begin{array}{l}\text { No. } 1 \text { Tahoen ke } \\
23\end{array}$ & & $\begin{array}{l}\text { Sokongan dari bg. } \\
\text { Pemoeda }\end{array}$ & 170 & 18 \\
\hline $\begin{array}{l}\mathrm{H} \cdot \mathrm{B} \\
\text { Moehammadijah }\end{array}$ & & Sokongan dari groep & 170 & 18 \\
\hline $\begin{array}{l}\text { Moeh arram } \\
1360 \mathrm{H}\end{array}$ & & Sokongan dari bg. 'Aisjijah & 174 & 20 \\
\hline \multirow[t]{2}{*}{ (Februari 1941) } & $\begin{array}{l}\text { Seroean memper- } \\
\text { sigreakan sokongan }\end{array}$ & 1 & 31 & 21 \\
\hline & & Daeah Soerabaia & 2 & 32 \\
\hline
\end{tabular}

DINIKA, Volume 3, Number 3, September - December 2018 


\begin{tabular}{|c|c|c|c|c|}
\hline & & Daerah Basoeki & 3 & 32 \\
\hline & & $\begin{array}{l}\text { Hasil gerakan menerima } \\
\text { dan membagi Zakat Fitrah }\end{array}$ & 6 & 34 \\
\hline & & Verslag Tahoenan & 17 & 39 \\
\hline & & $\begin{array}{l}\text { Tjabang dan Groep } \\
\text { Moehammadijah tahoen } \\
1940\end{array}$ & 17 & 39 \\
\hline & & Tjabang dan Groep & 18 & 40 \\
\hline & & $\begin{array}{l}\text { Perhitoengan Tjabang dan } \\
\text { groep Moehammadijah th } \\
1939 \text { sampai } 1940\end{array}$ & 30 & 46 \\
\hline & & $\begin{array}{l}\text { Halaman Pemoeda dan } \\
\text { roewangan 'Aisjijah } \\
\end{array}$ & 31 & 46 \\
\hline & & Potret Congres & 33 & 47 \\
\hline & & Ma'loemat ke V & 34 & 48 \\
\hline & Soeara Moehammadijah & Daerah Kediri & 190 & 30 \\
\hline $\begin{array}{l}\text { No. } 2 \text { Tahoen ke } \\
23\end{array}$ & & Daerah Semarang & 192 & 31 \\
\hline $\begin{array}{l}\text { H.B. } \\
\text { Moehammadijah }\end{array}$ & & $\begin{array}{l}\text { Daerah Poelau-poelau } \\
\text { Soenda }\end{array}$ & 193 & 31 \\
\hline Shafar $1360 \mathrm{H}$ & & Daerah Djawa Barat & 195 & 32 \\
\hline \multirow[t]{11}{*}{ (Maart 1941) } & $\begin{array}{l}\text { Tanfidz poetoesan } \\
\text { Congres } \\
\text { Moehammadijah ke-29 } \\
\end{array}$ & 37 & 49 & 33 \\
\hline & & $\begin{array}{l}\text { Poetoesan } \\
\text { Moehammadijah }\end{array}$ & 38 & 50 \\
\hline & & $\begin{array}{l}\text { Poetoesan Bahagian } \\
\text { Pemoeda }\end{array}$ & 40 & 51 \\
\hline & & $\begin{array}{l}\text { Poetoesan bahagian } \\
\text { 'Aisjijah }\end{array}$ & 42 & 52 \\
\hline & & Poetoesan Madjlis Tardjih & 45 & 53 \\
\hline & & Bahagian 'Aisjijah & 46 & 54 \\
\hline & & Bahagian Pemoeda & 51 & 56 \\
\hline & & $\begin{array}{l}\text { Adres bg. Pemoeda dan } \\
\text { bg. 'Aisjijah } \\
\end{array}$ & 54 & 58 \\
\hline & & $\begin{array}{l}\text { Penjigeraan pengiriman } \\
\text { verslag }\end{array}$ & 54 & 58 \\
\hline & & Sokongan Oentoek S.M. & 54 & 58 \\
\hline & & Roewangan 'Aisjijah: & 220 & \\
\hline \multirow[t]{3}{*}{$\begin{array}{l}\text { Daerah } \\
\text { Soerabaia }\end{array}$} & 55 & 58 & 221 & \\
\hline & & $\begin{array}{l}\text { Pengiriman Potoesan } \\
\text { Conferentie }\end{array}$ & 56 & 59 \\
\hline & & Halaman Pemoeda: & 224 & 47 \\
\hline
\end{tabular}

DINIKA, Volume 3, Number 3, September - December 2018 


\begin{tabular}{|c|c|c|c|c|}
\hline \begin{tabular}{|l|} 
Daerah \\
Soerabaja
\end{tabular} & 57 & 59 & 224 & 47 \\
\hline & & Daerah Besoeki & 58 & \\
\hline & & Verantwoording & & 62 \\
\hline & Soeara Moehammadijah & Daerah Atjeh & 228 & 49 \\
\hline $\begin{array}{l}\text { No. } 3 \text { Tahoen ke } \\
23\end{array}$ & & Gelora Soekma & 231 & 50 \\
\hline $\begin{array}{l}\mathrm{H} \\
\text { Moehammadijah }\end{array}$ & & $\begin{array}{l}\text { Shahifah Tardjih } \\
\text { Siaran Officieel dari H.B. } \\
\text { Moehammadijah }\end{array}$ & 233 & 51 \\
\hline R.Awal $1360 \mathrm{H}$ & & Ma'loemat & 234 & 52 \\
\hline \multirow[t]{10}{*}{ (April 1941) } & Fihrasat & & & 53 \\
\hline & & $\begin{array}{l}\text { Soesoenan Hoofdbestuur } \\
\text { Moehammadijah }\end{array}$ & 61 & \\
\hline & & Gedoeng Moehammadijah & 61 & \\
\hline & & $\begin{array}{l}\text { Potoesan Conferentie } \\
\text { Daerah }\end{array}$ & 61 & \\
\hline & & Sidang Tanwir & 61 & \\
\hline & & $\begin{array}{l}\text { Peroebahan Statuten dan } \\
\text { Huishoudelijk Teglement } \\
\text { Moehammadijah }\end{array}$ & 62 & \\
\hline & & $\begin{array}{l}\text { Penerimaan wang } \\
\text { sokongan Soeara } \\
\text { Moehammadijah dalam } \\
\text { taoen } 1940\end{array}$ & 66 & \\
\hline & & Daerah Iboe Tempat & 69 & \\
\hline & & Daerah Iboe Tempat & 70 & \\
\hline & & Halaman Pemoeda: & 243 & 56 \\
\hline \multirow[t]{5}{*}{ 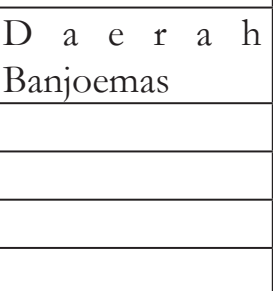 } & 72 & & 244 & 57 \\
\hline & & Sen-Pemoeda & 73 & \\
\hline & & H.W. dan Perkino & 74 & \\
\hline & & Persediaan Lainnja & 75 & \\
\hline & Soeara Moehammadijah & Daerah Atjeh & 249 & 59 \\
\hline $\begin{array}{l}\text { No. } 4 \text { Tahoen ke } \\
23\end{array}$ & & Daerah Soerakarta & 251 & 60 \\
\hline \begin{tabular}{|l|} 
H.B. \\
Moehammadijah
\end{tabular} & & $\begin{array}{l}\text { Halaman Pemoeda: } \\
\text { Album Peringatan }\end{array}$ & 252 & 61 \\
\hline R.Achir $1360 \mathrm{H}$ & & Daerah Semarang & 252 & 61 \\
\hline \multirow[t]{5}{*}{ (Mei 1941) } & Fihrasah & & 63 & 61 \\
\hline & & $\begin{array}{l}\text { Sokongan Fonds } \\
\text { Moehadjirin kolonisatie }\end{array}$ & 77 & 64 \\
\hline & & Daerah Tapanoeli & 78 & 65 \\
\hline & & Kas Verantwoording H.B. & 80 & 66 \\
\hline & & Daerah Benkoelen & 81 & 66 \\
\hline
\end{tabular}




\begin{tabular}{|c|c|c|c|c|}
\hline & & Daerah Celebes Selatan & 82 & 67 \\
\hline & & Daerah Borneo Selatan & 88 & 70 \\
\hline & & $\begin{array}{l}\text { Hoofdcomite Franco } \\
\text { 'Amal Moehammadijah }\end{array}$ & 91 & 71 \\
\hline & & $\begin{array}{l}\text { Pengiriman Verslag } \\
\text { tahoenan }\end{array}$ & 91 & 71 \\
\hline & & Daerah Koebra & 92 & 72 \\
\hline & & Sokongan S.M. & 93 & 72 \\
\hline & & Halaman Pemoeda: & 273 & \\
\hline \multirow{13}{*}{$\begin{array}{l}\text { Soesoenan } \\
\text { Madjlis }\end{array}$} & 95 & 73 & 275 & \\
\hline & & $\begin{array}{l}\text { Kantor H.B. Madjlis } \\
\text { Pemoeda }\end{array}$ & 95 & 73 \\
\hline & & Hal Conferentie Daerah & 95 & 73 \\
\hline & & Siaran Berkala & 96 & 74 \\
\hline & & Pendjelasan & 96 & 74 \\
\hline & & Daerah Iboe Tempat & 96 & 74 \\
\hline & & Daerah Tapanoeli & 98 & 75 \\
\hline & & $\begin{array}{l}\text { Instructive Conferentie } \\
\text { district Pemoeda } \\
\text { Moehammadijah }\end{array}$ & 99 & 75 \\
\hline & & Daerah Celebes Selatan & 101 & 76 \\
\hline & & $\begin{array}{l}\text { Sekolah-sekolah } \\
\text { Moehammadijah di } \\
\text { Jogjakarta (Dengan } \\
\text { Internaat) }\end{array}$ & & 78 \\
\hline & & $\begin{array}{l}\text { Process verbal verificatie } \\
\text { commissie } 1939\end{array}$ & & 79 \\
\hline & & Verantwoording & & 79 \\
\hline & Soeara Moehammadijah & Rapport gerakan qoerban & 304 & \\
\hline $\begin{array}{l}\text { No. } 5 \text { Tahoen ke } \\
23\end{array}$ & & Sokongan congres & & \\
\hline $\begin{array}{l}\text { H.B. } \\
\text { Moehammadijah }\end{array}$ & \begin{tabular}{|l} 
Soeara \\
Moehammadijah \\
No. 12 Tahoen ke 23 \\
H.B. Moehammadijah \\
Dz. Hidjah $1360 \mathrm{H}$ \\
(Januari 1942) \\
\end{tabular} & $\begin{array}{l}\text { Tidak langsoengnja } \\
\text { Congres }\end{array}$ & 305 & \\
\hline Dj. Awal $1360 \mathrm{H}$ & & Daerah Iboe Tempat & 306 & \\
\hline \multirow[t]{5}{*}{ (Juni 1941) } & Fihrasah & & 81 & \\
\hline & & Sidang Tanwir & 105 & 82 \\
\hline & & Daerah Banjoemas & 106 & 83 \\
\hline & & Sokongan S.M. & 107 & 83 \\
\hline & & $\begin{array}{l}\text { Hoofdcomite Congres } \\
\text { Moehammadijah }\end{array}$ & 113 & 86 \\
\hline
\end{tabular}

DINIKA, Volume 3, Number 3, September - December 2018 


\begin{tabular}{|c|c|c|c|c|}
\hline & & $\begin{array}{l}\text { Fonds Moehadjirin } \\
\text { kolonisatie }\end{array}$ & 113 & 86 \\
\hline & & \begin{tabular}{|l|} 
Penagian pengiriman \\
Verslag tahoenan
\end{tabular} & 113 & 86 \\
\hline & & Roewangan 'Aisjijah: & 311 & \\
\hline \multirow{7}{*}{ Madjlis 'Aisjiijah } & 114 & 87 & 311 & \\
\hline & & Bahagian 'Aisjijah & 114 & 87 \\
\hline & & $\begin{array}{l}\text { Arti mengoelangi } \\
\text { poetoesan Congress }\end{array}$ & 114 & 87 \\
\hline & & $\begin{array}{l}\text { Sokongan tjabang dan } \\
\text { groep 'Aisjijah dan } \\
\text { sokongan madjlis 'Aisjijah } \\
\text { kepada P.A.D. }\end{array}$ & 115 & 87 \\
\hline & & $\begin{array}{l}\text { Waktoe 'Aisjijah diakoei } \\
\text { menjdai bahagiannja } \\
\text { Moehammadijah }\end{array}$ & 115 & 87 \\
\hline & & Daerah Benkoelen & 116 & 88 \\
\hline & & Halaman Pemoeda: & & \\
\hline \multirow[t]{3}{*}{$\begin{array}{l}\text { H.W. dan } \\
\text { Perkino }\end{array}$} & 119 & 89 & & \\
\hline & & $\begin{array}{l}\text { Seroean kepada Sdr. } \\
\text { Menteri Daerah }\end{array}$ & 119 & 89 \\
\hline & Soeara Moehammadijah & & & \\
\hline \multicolumn{5}{|l|}{$\begin{array}{l}\text { No. } 6 \text { Tahoen ke } \\
23\end{array}$} \\
\hline \multicolumn{5}{|l|}{$\begin{array}{l}\text { H.B. } \\
\text { Moehammadijah }\end{array}$} \\
\hline \multicolumn{5}{|l|}{$\begin{array}{l}\text { Dj. Achir } 1360 \\
\mathrm{H}\end{array}$} \\
\hline \multirow[t]{4}{*}{ (Juli 1941) } & Nama-nama gerakan & 121 & 90 & \\
\hline & & $\begin{array}{l}\text { Penerimaan verslag } \\
\text { tahoenan }\end{array}$ & 123 & 91 \\
\hline & & Aandeel kapal hadji & 126 & 93 \\
\hline & & Halaman pemoeda: & & \\
\hline \multirow[t]{8}{*}{$\begin{array}{l}\text { Memperboeah } \\
\text { kepotoesan } \\
\text { Congres ke-29 } \\
\end{array}$} & 128 & 94 & & \\
\hline & & Daerah Borneo Selatan & 129 & 94 \\
\hline & & Daerah Pekalongan & 130 & 95 \\
\hline & & Daerah Benkoelen & 131 & 95 \\
\hline & & Daerah Soerakarta & 132 & 96 \\
\hline & & Daerah Kediri & 133 & 96 \\
\hline & & Ma'loemat & 135 & 97 \\
\hline & Soeara Moehammadijah & & & \\
\hline
\end{tabular}

DINIKA, Volume 3, Number 3, September - December 2018 


\begin{tabular}{|c|c|c|c|c|}
\hline \begin{tabular}{|l|} 
No.7 Tahoen ke \\
23
\end{tabular} & & & & \\
\hline $\begin{array}{lc}\mathrm{H} & \cdot \\
\text { Moehammadijah }\end{array} \mid$ & & & & \\
\hline Radjab $1360 \mathrm{H}$ & & & & \\
\hline (Aug. 1941) & Nomer Franco 'Amal & 137 & 98 & \\
\hline & & $\begin{array}{l}\text { Ledenvergadering oentoek } \\
\text { Franco 'Amal }\end{array}$ & 137 & 98 \\
\hline & & Njanjian Franco 'Amal & 138 & 99 \\
\hline & & $\begin{array}{l}\text { Soerat-soerat } \\
\text { Moehammadijah }\end{array}$ & 138 & 99 \\
\hline & & $\begin{array}{l}\text { Franco 'Amal } \\
\text { Moehammadijah }\end{array}$ & 139 & 99 \\
\hline & & $\begin{array}{l}\text { Woedjod franco 'Amal } \\
\text { Moehammadijah }\end{array}$ & 140 & 100 \\
\hline & & $\begin{array}{l}\text { Hoofdcomite franco 'amal } \\
\text { Moehammadijah }\end{array}$ & 141 & 100 \\
\hline \begin{tabular}{|l|} 
Soeara \\
Moehammadijah \\
36 \\
\end{tabular} & & $\begin{array}{l}\text { Bersama-sama } \\
\text { Ledenvergadering } \\
\text { Moehammadijah }\end{array}$ & 148 & 4 \\
\hline & & Menghadapi batoe oedjian & 149 & 4 \\
\hline & & Waktoe berlakoenja & 155 & 7 \\
\hline & & Postelad dan beriefkaart & 155 & 7 \\
\hline & Soeara Moehammadijah & & & \\
\hline \begin{tabular}{|l|} 
No. 8 Tahoen ke \\
23
\end{tabular} & & & & \\
\hline \begin{tabular}{|l|} 
H.B. \\
Moehammadijah \\
\end{tabular} & & & & \\
\hline Sja'ban $1360 \mathrm{H}$ & & & & \\
\hline (Sept. 1941) & Fihrasat & & 8 & \\
\hline & & Sokongan S.M. & 153 & 9 \\
\hline & & $\begin{array}{l}\text { Penjelesaian Congres } \\
\text { ke-29 }\end{array}$ & 153 & 9 \\
\hline & & Soerat H.C.C.M. No. 19 & 154 & 10 \\
\hline & & $\begin{array}{l}\text { Anggauta H.C.C.M. } \\
\text { merangkap C.v.O. }\end{array}$ & 155 & 10 \\
\hline & & Idem 'Aisjijah & 155 & 10 \\
\hline & & $\begin{array}{l}\text { Kedjadian-kedjadian } \\
\text { penting }\end{array}$ & 156 & 11 \\
\hline & & $\begin{array}{l}\text { Telegram } 2 \text { jang } \\
\text { membahagiakan Congres } \\
\text { dengan mengoetjapka }\end{array}$ & 158 & 12 \\
\hline
\end{tabular}

DINIKA, Volume 3, Number 3, September - December 2018 


\begin{tabular}{|c|c|c|c|c|}
\hline & & $\begin{array}{l}\text { Soerat-soerat jang } \\
\text { mengoetjapkan selamat } \\
\text { Congres serta melahirkan } \\
\text { berhalangan }\end{array}$ & 160 & 13 \\
\hline & & Koendjoengan Congres & 161 & 13 \\
\hline & & Soembangan-soembangan & 162 & 14 \\
\hline & & $\begin{array}{l}\text { Derma jang woedjoed } \\
\text { wang }\end{array}$ & 166 & 16 \\
\hline & & Sokongan dari Tjabang & 168 & 17 \\
\hline & & Sokongan dari bg. 'Aisjijah & 168 & 17 \\
\hline & & $\begin{array}{l}\text { Sokongan dari bg. } \\
\text { Pemoeda }\end{array}$ & 170 & 18 \\
\hline & & Sokongan dari groep & 170 & 18 \\
\hline & & Sokongan dari bg. 'Aisjiijah & 174 & 20 \\
\hline & & $\begin{array}{l}\text { Sokongan dari groep } \\
\text { Pemoeda }\end{array}$ & 176 & 21 \\
\hline & & Derma wang & 178 & 22 \\
\hline & & Kas Veraatwoonding & 182 & 24 \\
\hline & & $\begin{array}{l}\text { Soerat Hoofbestuur } \\
\text { Moehammadijah }\end{array}$ & & 25 \\
\hline & & $\begin{array}{l}\text { Toeroenan } \\
\text { rechtpersoonlikheid van } \\
\text { vereenigingen }\end{array}$ & & 26 \\
\hline & & $\begin{array}{l}\text { Franco ‘Amal } \\
\text { Moehammadijah }\end{array}$ & & 26 \\
\hline & & Waktoe Berlakoenja & & 27 \\
\hline & & Postblad dan briefkaart & & 27 \\
\hline & Soeara Moehammadijah & & & \\
\hline $\begin{array}{l}\text { No. } 9 \text { Tahoen ke } \\
23\end{array}$ & & & & \\
\hline $\begin{array}{l}\text { H.B. } \\
\text { Moehammadijah }\end{array}$ & & & & \\
\hline Ramdlan1360 H & & & & \\
\hline (October 1941) & Oendangan Congres & 185 & 27 & \\
\hline & & Daerah Boerneo Timoer & 187 & 28 \\
\hline & & Daerah Soerakarta & 189 & 29 \\
\hline & & Daerah Kediri & 190 & 30 \\
\hline & & Daerah Semarang & 192 & 31 \\
\hline & & $\begin{array}{l}\text { Daerah Poelau-poelau } \\
\text { Soenda }\end{array}$ & 193 & 31 \\
\hline & & Daerah Djawa Barat & 195 & 32 \\
\hline & & $\begin{array}{l}\text { Daerah Lampoeng dan } \\
\text { Palembang }\end{array}$ & \begin{tabular}{|l|}
197 \\
\end{tabular} & 33 \\
\hline & & $\begin{array}{l}\text { Franco 'Amal } \\
\text { Moehammadijah }\end{array}$ & 201 & 35 \\
\hline
\end{tabular}

DINIKA, Volume 3, Number 3, September - December 2018 


\begin{tabular}{|c|c|c|c|c|}
\hline & & Daerah Atjeh & 202 & 36 \\
\hline & & Daerah Besoeki & 208 & 39 \\
\hline & & Daerah Sumatra Timoer & 210 & 40 \\
\hline & & Daerah Minangkabau & 213 & 41 \\
\hline & & Daerah Riau Indragiri & 215 & 42 \\
\hline & & Pertanjaan pereconomiean & 218 & 44 \\
\hline & & Roeangan 'Aisjijah: & & \\
\hline \multirow{5}{*}{$\begin{array}{l}\text { Daerah Celebes } \\
\text { Selatan }\end{array}$} & 219 & 44 & & \\
\hline & & Daerah Tapanoeli & 220 & \\
\hline & & Daerah Borneo Selatan & 220 & \\
\hline & & Daerah Kediri & 221 & \\
\hline & & Halaman Pemoeda: & & \\
\hline \multirow{8}{*}{$\begin{array}{l}\text { Hasil Sen } \\
\text { Pemoeda }\end{array}$} & 222 & 46 & & \\
\hline & & Adanja verslag ringkas & 224 & 47 \\
\hline & & Daerah Borneo Timur & 224 & 47 \\
\hline & & Daerah Soerabaja & 225 & 47 \\
\hline & & $\begin{array}{l}\text { Darah Lampoeng } \\
\text { Palembang }\end{array}$ & 226 & 48 \\
\hline & & Daerah Atjeh & 228 & 49 \\
\hline & & Gelora Soekma & 231 & 50 \\
\hline & & Shahifah Tardjih & & \\
\hline \multirow{3}{*}{$\begin{array}{l}\text { Siaran Officieel } \\
\text { dari H.B. } \\
\text { Moehammadijah }\end{array}$} & 233 & 51 & & \\
\hline & & Ma'loemat & 234 & 52 \\
\hline & Soeara Moehammadijah & & & \\
\hline \multicolumn{5}{|l|}{$\begin{array}{l}\text { No. } 10 \text { Tahoen } \\
\text { ke } 23\end{array}$} \\
\hline \multicolumn{5}{|l|}{$\begin{array}{l}\text { H.B. } \\
\text { Moehammadijah }\end{array}$} \\
\hline \multicolumn{5}{|l|}{ Sjawal $1360 \mathrm{H}$} \\
\hline \multirow[t]{6}{*}{ (Nov. 1941) } & $\begin{array}{l}\text { Pengoempoelan bekas } \\
\text { franco 'Amal }\end{array}$ & 237 & 53 & \\
\hline & & Daerah Madioen & 237 & 53 \\
\hline & & Daerah Pasoereoan & 240 & 55 \\
\hline & & Rapat Tardjih & 241 & 55 \\
\hline & & Hampir toetoep tahoen & 241 & 55 \\
\hline & & Roeangan 'Aisjijah: & & \\
\hline \multirow{4}{*}{$\begin{array}{l}\text { Daerah } \\
\text { Pasoeroean }\end{array}$} & 242 & 56 & & \\
\hline & & & & \\
\hline & & Daerah Pekalongan & 242 & 56 \\
\hline & & Daerah Djawa Barat & 242 & 56 \\
\hline
\end{tabular}

DINIKA, Volume 3, Number 3, September - December 2018 


\begin{tabular}{|c|c|c|c|c|}
\hline & & Daerah Madioen & 243 & 56 \\
\hline & & Daerah Besoeki & 243 & 56 \\
\hline & & Daerah Minangkabau & 244 & 57 \\
\hline & & Daerah Riouw & 247 & 58 \\
\hline & & $\begin{array}{l}\text { Daerah Lampoeng } \\
\text { Palembang }\end{array}$ & 248 & 59 \\
\hline & & Daerah Madioen & 249 & 59 \\
\hline & & Daerah Atjeh & 249 & 59 \\
\hline & & Daerah Soerakarta & 251 & 60 \\
\hline & & Halaman Pemoeda: & & \\
\hline \multirow[t]{10}{*}{$\begin{array}{l}\text { Album } \\
\text { Peringatan }\end{array}$} & 252 & 61 & & \\
\hline & & Daerah Semarang & 252 & 61 \\
\hline & & $\begin{array}{l}\text { Daerah Soematra Pesisir } \\
\text { Timur }\end{array}$ & 253 & 61 \\
\hline & & Daerah Basoeki & 254 & 62 \\
\hline & & Daerah Minangkabau & 255 & 62 \\
\hline & & Daerah Riauw Indragiri & 257 & 63 \\
\hline & & Shahifa Tardjieh & 259 & 64 \\
\hline & & $\begin{array}{l}\text { Penjelesaian oeroesan } \\
\text { franco 'Amala } \\
\text { Moehammadijah }\end{array}$ & 260 & 65 \\
\hline & & $\begin{array}{l}\text { Persiapan persediaan } \\
\text { Congres Moehammadijah } \\
\text { ke-30 }\end{array}$ & 262 & 66 \\
\hline & & Pengadjaran Agama Islam & & \\
\hline \multirow[t]{2}{*}{$\begin{array}{l}\text { di Roemah } \\
\text { Tangga dan di } \\
\text { Sekolah Rendah } \\
\text { Oemoem } \\
\end{array}$} & & 68 & & \\
\hline & Soeara Moehammadijah & & & \\
\hline \multicolumn{5}{|l|}{$\begin{array}{ll}\text { No. } 11 & \text { Tahoen } \\
\text { ke } 23 & \\
\end{array}$} \\
\hline \multicolumn{5}{|l|}{$\begin{array}{l}\text { H.B. } \\
\text { Moehammadijah }\end{array}$} \\
\hline \multicolumn{5}{|l|}{$\begin{array}{l}17 \text { Dz. Qa'dah } \\
1360 \mathrm{H}\end{array}$} \\
\hline \multirow[t]{3}{*}{$\begin{array}{l}\text { (6 December } \\
\text { 1941) }\end{array}$} & Fihrasat & & & \\
\hline & & $\begin{array}{l}\text { Praeadvies oentoek } \\
\text { Congres ke-30 }\end{array}$ & 269 & \\
\hline & & $\begin{array}{l}\text { Pendidikan dan } \\
\text { penjiaran Islam dalam } \\
\text { kalangankeloearga } \\
\text { Moehammadijah } \\
\end{array}$ & 270 & \\
\hline
\end{tabular}

DINIKA, Volume 3, Number 3, September - December 2018 


\begin{tabular}{|c|c|c|c|}
\hline & & $\begin{array}{l}\text { Pertolongan kesengsaraan } \\
\text { oemoem }\end{array}$ & 273 \\
\hline & & Pertolongan isteri bersalin & 275 \\
\hline & & Persiapan pertolongan & 277 \\
\hline & & $\begin{array}{l}\text { Pendidikan dan } \\
\text { pengadjaran }\end{array}$ & 278 \\
\hline & & $\begin{array}{l}\text { dari hal pendidikan dan } \\
\text { pengadjaran }\end{array}$ & 279 \\
\hline & & $\begin{array}{l}\text { Memperbaiki pendidikan } \\
\text { dan peladjaran }\end{array}$ & 282 \\
\hline & & $\begin{array}{l}\text { Sedikit dari hal } \\
\text { pengadjaran Agama }\end{array}$ & 287 \\
\hline & & $\begin{array}{l}\text { Pendidikan dan } \\
\text { pengadjaran }\end{array}$ & 294 \\
\hline & & $\begin{array}{l}\text { Siaran Islam kepada } \\
\text { sekolah-sekolah } \\
\text { atau moerid-moerid } \\
\text { dari loewar sekolah } \\
\text { Moehammadijah }\end{array}$ & 298 \\
\hline & & Penjiaran Islam & \\
\hline $\begin{array}{l}\text { S a mboe ngan } \\
\text { moeka } 273\end{array}$ & 299 & & \\
\hline & & $\begin{array}{l}\text { Qa'idah Madjlis } \\
\text { Economie }\end{array}$ & 301 \\
\hline & & Keterangan Praeadvies & 302 \\
\hline & & \begin{tabular}{|l|} 
Sokongan fonds \\
Moehadjirin Kolonisasi
\end{tabular} & 303 \\
\hline & & Rapport gerakan qoerban & 304 \\
\hline & & Sokongan congres & \\
\hline & Soeara Moehammadijah & & \\
\hline $\begin{array}{ll}\text { No. } 12 & \text { Tahoen } \\
\text { ke } 23 & \\
\end{array}$ & & & \\
\hline $\begin{array}{l}\mathrm{H} \\
\text { Moehammadijah }\end{array}$ & & & \\
\hline $\begin{array}{l}\text { Dz. Hidjah } 1360 \\
\mathrm{H}\end{array}$ & & & \\
\hline (Januari 1942) & $\begin{array}{l}\text { Tidak langsoengnja } \\
\text { Congres }\end{array}$ & 305 & \\
\hline & & Daerah Iboe Tempat & 306 \\
\hline & & Daerah Soerakarta & 307 \\
\hline & & Rapport Tardjih & 308 \\
\hline & & $\begin{array}{l}\text { Rapport Gerakan } \\
\text { Qoerban }\end{array}$ & 308 \\
\hline & & Verslag'Tahoenan 1941 & 308 \\
\hline
\end{tabular}

DINIKA, Volume 3, Number 3, September - December 2018 


\begin{tabular}{|l|l|l|l|l|}
\hline & & $\begin{array}{l}\text { Franco 'Amal } \\
\text { Moehammadijah }\end{array}$ & 308 & \\
\hline & & Nomer Pertoekaran & 309 & \\
\hline & & Penerimaan boekoe & 310 & \\
\hline & $\begin{array}{l}\text { Poetoesan Conferentie } \\
\text { Moehammadijah }\end{array}$ & 311 & \\
\hline & & $\begin{array}{l}\text { Sokongan S.M. tahoen } \\
1360\end{array}$ & 311 & \\
\hline & Tjabang dan Groep 1941 & 312 & \\
\hline & & Penoetoep Tahoen & 312 & \\
\hline Daerah Atjeh & 313 & Shahifah Tardjih: & . & \\
\hline & & $\begin{array}{l}\text { Penerimaan wang } \\
\text { sokongan dan langganan } \\
\text { S.M. 1360 }\end{array}$ & 315 & \\
\hline & $\begin{array}{l}\text { Tjabang dan groep } \\
\text { Moehammadijah dalam } \\
\text { tahoen 1941 }\end{array}$ & 325 & \\
\hline & Ma'loemat & & \\
\hline & & & & \\
\hline
\end{tabular}


DINIKA, Volume 3, Number 3, September - December 2018 